\title{
Influence of pH Preparation on the Photo-Response of Electrodeposited Titanium Dioxide $\left(\mathrm{TiO}_{2}\right)$ Thin Films
}

\author{
Toto Mabiala Masiala ${ }^{1, ~ *}$, Albert Kazadi Mukenga Bantu ${ }^{1}$, Gracian Ekoko Bakambo, \\ Jérémie Muswema Lunguya ${ }^{2}$, Joseph Lobo Kanza Kanza², Omer Mvele Muamba ${ }^{2}$ \\ ${ }^{1}$ Department of Physics, Faculty of Sciences, University of Kinshasa, Kinshasa, Democratic Republic of Congo \\ ${ }^{2}$ Department of Chemistry, Faculty of Sciences, University of Kinshasa, Kinshasa, Democratic Republic of Congo
}

Email address:

totomabiala@yahoo.fr (T. M. Masiala)

${ }^{*}$ Corresponding author

\section{To cite this article:}

Toto Mabiala Masiala, Albert Kazadi Mukenga Bantu, Gracian Ekoko Bakambo, Jérémie Muswema Lunguya, Joseph Lobo Kanza Kanza, Omer Mvele Muamba. Influence of pH Preparation on the Photo-Response of Electrodeposited Titanium Dioxide $\left(\mathrm{TiO}_{2}\right) \mathrm{Thin}_{\mathrm{Films}}$ International Journal of Materials Science and Applications. Vol. 5, No. 5, 2016, pp. 207-213. doi: 10.11648/j.ijmsa.20160505.15

Received: August 12, 2016; Accepted: August 30, 2016; Published: September 29, 2016

\begin{abstract}
The anodic oxidation method has been used to prepare thin films of titanium dioxide $\left(\mathrm{TiO}_{2}\right)$ in acid and alkaline electrolytes. The influence of $\mathrm{pH}$ on the structure, the morphology and the photo response of the deposited $\mathrm{TiO}_{2}$ has been evaluated by measuring the current density. The experimental results showed that the photo current response was $\mathrm{pH}$ dependent. The acid electrolytes being the best medium in producing stable oxide films with good adhesion to titanium metal substrate and good charging rate and current density.
\end{abstract}

Keywords: Titanium Films, Anodic Oxidation, Photo Response, pH Values

\section{Introduction}

The thin layers and nanoparticles of the transition metals oxide arouse a very big interest nowadays both on the theoretical and experimental point of view [1-2].

On the experimental plan, the understanding of the behavior of transition metals from which they arise is far from being satisfactory even though these oxides show very interesting properties. In their great majority these oxides show not only a semiconducting behavior, but also a photo-catalytic activity. This last property is particularly very important in the photolysis of the water, the decomposition of organic pollutants, and the clean-up of the air [3-6].

The precursory works of Brattan and Garret on the physical behavior of semiconductors, more specifically some germanium in contact with aqueous solution are references in this field [7]. The reference regarding the metal semiconductors of $3 \mathrm{~d}$ oxides has for origin the work realized by Fujishima and Honda [8], whose were the first to use a single crystalline $\mathrm{TiO}_{2}$ photo anode for electro-catalytic decomposition of water under the influence of the external applied anode potential. The application of such as anodic bias was found to increase the photo-catalytic efficiency of $\mathrm{TiO}_{2}$ thin layers for degrading undesirable pollutants in aqueous solution.

This works were realized in order to use and store the solar energy and were the starting point of several researches up today.

Currently, researches are mainly focused on three directions: 1) storage and use of solar energy (photo-galvanic cells), 2) photo-catalysis by induction of photo-activated reactions by natural or artificial catalyst, 3) the manufacturing of electronic devices (sensors, nanocomponents) [9]. Regarding to the two first applications, titanium dioxide to its low cost and toxicity is the one with quasi-inalterability in the reaction medium; add to that his low cost and toxicity. Regarding to the two first applications, titanium dioxide to its low cost and toxicity is the one with quasi-inalterability in the reaction medium; add to that his low cost and toxicity.

However, their width forbidden band pulls that its activation is mainly made in the ultraviolet region of the solar spectrum. This characteristic is very exploited in the 
reflecting covers; but it constitutes a handicap for the first two aforesaid applications because the ultraviolet region represents on earth only approximately 3 to $8 \%$ of the solar spectrum. The major challenge of the various researches consists of optimization of the photo-response of the thin layers of $\mathrm{TiO}_{2}$. Several studies were able to show, and at least to suggest that both major handicaps shown by the $\mathrm{TiO}_{2}$ could be overcome by addition of ions drugs to return the photo-activation of $\mathrm{TiO}_{2}$ in the visible region by creation of the levels allowed in the forbidden band or still by nanometric aggregates with nanocovers of noble metals such as the silver or the gold [10]. The high affinity that Ti has for oxygen results in several oxide of various crystalline structures. In a natural atmosphere the thermodynamically stable oxide is $\mathrm{TiO}_{2}$, which can exist in three crystalline structures: anatase (tetragonal), rutile (tetragonal) and brookite (orthorhombic). In general, the anatase structure is obtained by anodic oxidation and the rutile structure is obtained too by anodic oxidation followed by a thermal treatment [11-13].

In the present investigation, a titanium (Ti) metal film is used as starting material to produce titanium dioxide on the surface of titanium metal by anodic oxidation. The processes produced the $\mathrm{TiO}_{2}$ films with a good adhesion with the titanium substrate, higher surface area, and good chemical stability, which enable its application as photo catalyst for the degradation of organic pollutants in wastewater purification.

The anodic films produced electrochemically are composed of two layers: the inner Titanium (Ti) oxide layer which is composed of anatase crystals and the outer Ti oxide layer are formed at the film/electrolyte interface. The latter is morphologically homogenous and composed of an amorphous oxide only. Anodizing of $\mathrm{Ti}$ involves an amorphous-to-crystalline transition in the oxide structure at relatively low voltage [11], [12], [14]. Furthermore, certain ions have for essential properties to inhibit the anatase transition shines, for example, the niobium [10]. If the photocatalysis is another phenomenon badly included in details, it is however admitted that the origin of this one is due really to a photo-activation of the heart by production of pair's electrons-holes within the semiconducting materials. In this work we focus on the regime of current during the electrodeposition process in order to be sure of the process of the semiconducting deposit. Then, we study the evolution of the photo-tension versus the time, with emphasis on the influence of $\mathrm{pH}$ of preparation on the photo- of response of the obtained titanium dioxide thin layers. This photoresponse will be highlighted by the measure of the photocurrent density and the photo-tension of various samples. All the samples were submitted to the same conditions of irradiation. Finally, we measure the photo-current density polarizing the device with a source of variable tension, in order to select the samples which display the best photocurrent density.

Section 2 is a short experiment details, section 3 will detail the presentation of our results and discussion, and section 4 is our conclusion.

\section{Experimental Details}

To prepare $\mathrm{TiO}_{2}$ thin films by the anodic oxidation method, $\mathrm{H}_{2} \mathrm{SO}_{4}$ and $\mathrm{NaOH}$ were selected as electrolytes. Titanium substrates were prepared from titanium plates of $0.5 \mathrm{~mm}$ thickness containing $\mathrm{Ti}(\geq 97 \%), \mathrm{N}(\leq 0.012 \%), \mathrm{C}(\leq 0.02 \%)$, $\mathrm{Si}(\leq 0.04 \%)$ and $\mathrm{Fe}(\leq 0.06 \%)$. They were cut into pieces of dimensions $3.5 \times 4.0 \mathrm{~cm}^{2}\left(14 \mathrm{~cm}^{2}\right)$ and were cleaned in chloroform and etched in hydrofluoric acid (4\%) for a period from 0.5 to 1 minute, depending on the required surface structure. They were rinsed in deionized water, and then ultrasonically cleaned in acetone before being immediately dried and analysed.

The electrodeposition was carried out at in a conventional cell, with platinum $(\mathrm{Pt})$ as counter electrode $(\mathrm{CE})$, and a saturated calomel electrode (SCE) as reference electrode, by direct anodization in potentiostatic mode according to the Figure 1 (a). Alls potentials are quoted with respect to SCE. The used cathode was a copper rectangular plate of 3.5-4.0 $\mathrm{cm}^{2}$ active area. The similar anode active surface area was the titanium metal sheet (working electrode WE). It was connected to the positive terminal of a direct current (DC) power supply. The cathode consists of a platinised cupper, which was inert in anodizing bath at a constant anodization current. When a voltage is applied, the titanium substrate is expected to react with water and forms an oxide layer o the metal surface. The anode and cathode, $8 \mathrm{~cm}$ distanced, were placed parallel in a Pyrex cell containing the electrolyte. In our previous work, we reported the room temperature preparation methods of the films deposited onto titanium sheet in acid and alkaline media. In this work the cooling fan was used to prevent the overheating of the solution on Pyrex cell [11-13].

The current densities generated during the electrodeposition were recorded using a digital ammeter during the deposit process. The Pyrex containing the electrolyte was extremely irradiated with a 125 watt pressure mercury ultraviolet lamp (model G-Z 125, $\lambda=370 \mathrm{~nm}$ ). This process helps to measure the photo-potential. The ultraviolet lamp was poisoned at a $20 \mathrm{~cm}$ distance from the aqueous electrolyte /catalyst, under a nearby angle of $90^{\circ}$ with respect to the surface electrode as shown in Figure 1 (b). The evolution of the photo-potential versus time was recorded by means of a digital voltmeter placed in parallel between the semiconducting electrode (working electrode: WE) and the platinum electrode (counter electrode). The corresponding charge rate is deduced by direct derivation of the data of the tension curve versus time. The measure of current-tension curve was made in similar configuration to that of the photodiode or classical diode, with this difference that the rate of variation of the applied tension is low to allow the rebalancing of charges interface between the semiconductor and the alkaline solution $(1 \mathrm{M}$ of $\mathrm{NaOH})$. The rate of variation of the tension is about $30 \mathrm{mV} / \mathrm{s}$ generated by an analogical integrator to operational amplifier. Figure 1 (c) illustrates the 
following device.
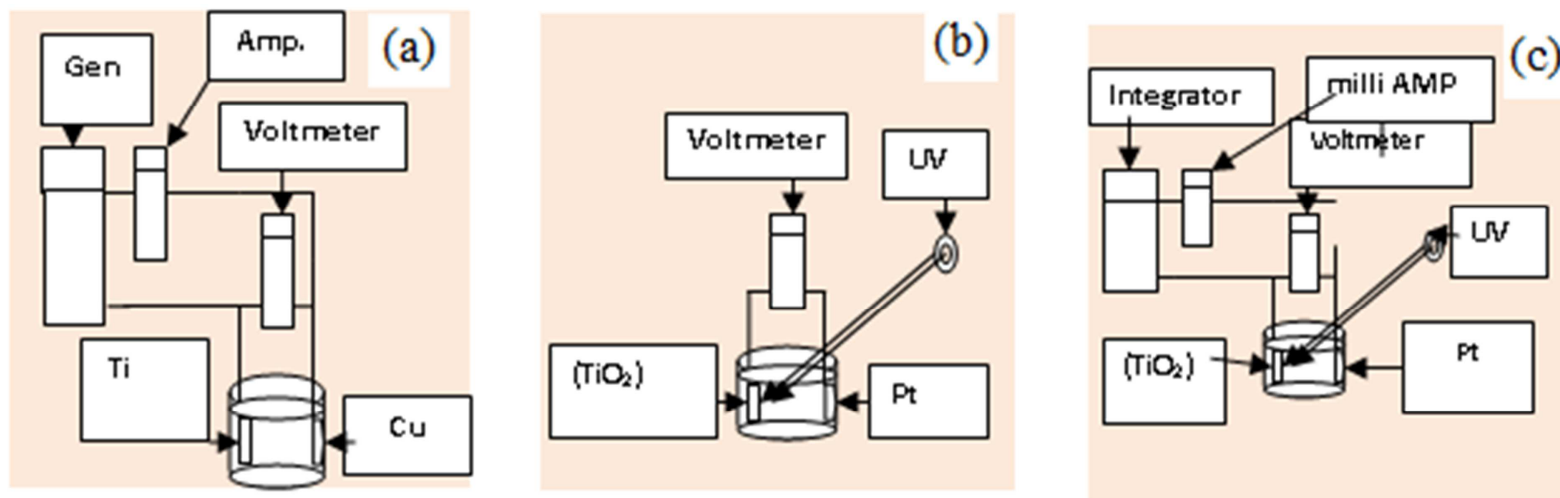

Figure 1. (a) Experimental schemes of electrodeposition (b) Photo-potential measurements and (c) current-tension curves measurements (Gen: generator; Amp: ammeter).

The phase identification of the coating layer was carried out on X-ray powder diffraction (XRD) patterns, using a D/MAX-2550 X-ray diffractometer with $\mathrm{Cu} \mathrm{K \alpha}$ radiation $(\lambda=1.54056 \AA)$ and nickel filter (Rigaku Co., Japan). The surface characterization of the electrodeposited samples was carried out using X-ray photoelectron spectroscopy (XPS) which was performed with a Thermo VG Scientific

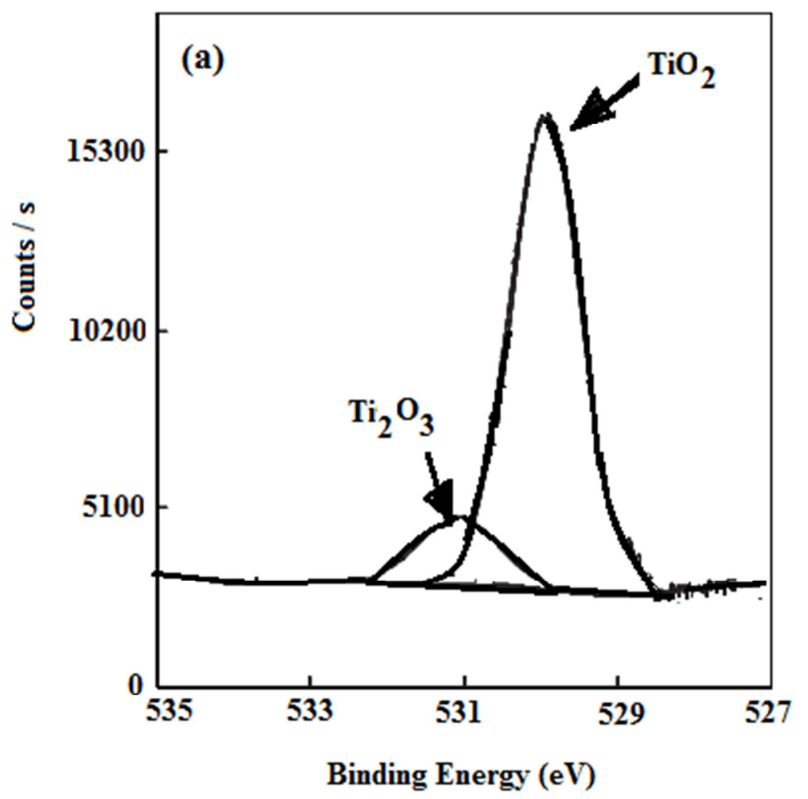

ESCALAB 250 spectrometer with a monochromatized $\mathrm{Al} \mathrm{K \alpha}$ X-ray source (1486.6eV energy).

It was expected to achieve a change of $\mathrm{Ti}^{3+} / \mathrm{Ti}^{4+}$ ratio in the $\mathrm{TiO}_{2}$ crystal structure, especially the surface states Ti $2 \mathrm{p}$ and $\mathrm{O} 1 \mathrm{~s}$. The crystal structure of $\mathrm{TiO}_{2}$ was examined by X-ray photoelectron spectroscopy; patterns were taken and shown in Figure 2.

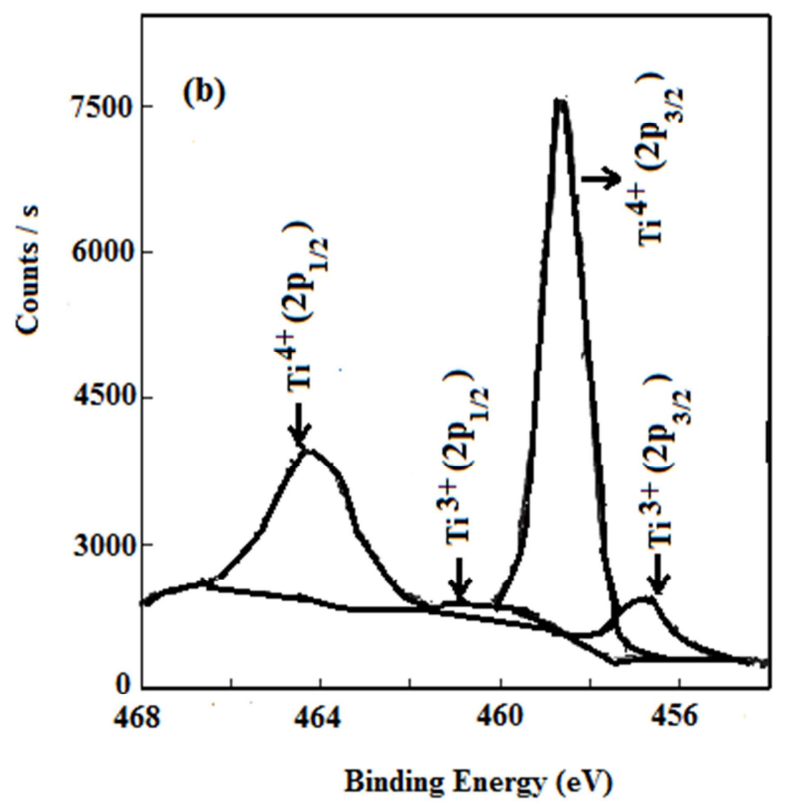

Figure 2. (a) Ols narrow scan XPS-spectra $\mathrm{TiO}_{2}$ and (b) narrow scan $\mathrm{Ti} 2 \mathrm{p}$ XPS-spectra $\mathrm{TiO}_{2}$.

From the Figure 2 (a), one can see that a peak-fitted O1s narrow scan XPS spectrum of $\mathrm{TiO}_{2}$ is observed. The O1s spectrum was fitted with two peaks, one relative to $\left[\mathrm{TiO}_{2}\right]$ (double bond: $\mathrm{O}=$ ) at $529.9 \mathrm{eV}$ and the other to $\left[\mathrm{Ti}_{2} \mathrm{O}_{3}\right]$ (simple bond: - - -) at $531.1 \mathrm{eV}$. The two peaks in O1s XPS spectrum were associated with two oxidation states of titanium $\left(\mathrm{Ti}^{4+}\right.$ and $\left.\mathrm{Ti}^{3+}\right)$.

The comparison of narrow scan Ti $2 p$ XPS spectrum of the prepared $\mathrm{TiO}_{2}$ is shown in Figure 2 (b). The spectrum of $\mathrm{TiO}_{2}$ sample shows four peaks relative to the $\mathrm{Ti}^{4+}\left(2 \mathrm{p}_{3 / 2}\right)$ at 458.6 $\mathrm{eV}, \mathrm{Ti}^{3+}\left(2 \mathrm{p}_{3 / 2}\right)$ at $456.7 \mathrm{eV}, \mathrm{Ti}^{3+}\left(2 \mathrm{p}_{1 / 2}\right)$ at $460.8 \mathrm{eV}$, and $\mathrm{Ti}^{4+}$ $\left(2 \mathrm{p}_{1 / 2}\right)$ at $464.2 \mathrm{eV}$. Both Ti $2 \mathrm{p}_{1 / 2}$ and Ti $2 \mathrm{p}_{3 / 2}$ states showed a change in $\mathrm{Ti}^{3+}$ and $\mathrm{Ti}^{4+}$.

The EDS results (not shown here) showed that there is 84.3 at. $\%$ of oxygen in $\mathrm{TiO}_{2}, 15.2$ at.\% of oxygen in $\mathrm{Ti}_{2} \mathrm{O}_{3}$ and 0.5 at. $\%$ of sulphur as impurity from the sulphuric acid electrolyte used for electrodeposition treatment.

It was found that the amount of $\mathrm{Ti}^{3+}$ states increased in $\mathrm{pH}$ 10.8 as a consequence of the electrodeposition treatment. The peak of $\mathrm{Ti}^{4+}\left(2 \mathrm{p}_{3 / 2}\right)$ at $458.6 \mathrm{eV}$ showed 54.8 at.\% of titanium in $\mathrm{TiO}_{2}$, peak of $\mathrm{Ti}^{4+}\left(2 \mathrm{p}_{1 / 2}\right)$ at $464.2 \mathrm{eV}$ showed 30.4 at.\% of titanium, peak of $\mathrm{Ti}^{3+}\left(2 \mathrm{p}_{3 / 2}\right)$ at $456.7 \mathrm{eV}$ showed 9.7 at.\% of 
titanium and the one of $\mathrm{Ti}^{3+}\left(2 \mathrm{p}_{1 / 2}\right)$ at $460.8 \mathrm{eV}$ showed 5.1 at. $\%$ of titanium.

The $\mathrm{Ti}^{3+}$ centers at the surface could enhance the oxygen chemisorptions and promote excited electrons, trapped by $\mathrm{O}_{2}$. This fact can additionally support the reduction of the bandgap energy of $\mathrm{TiO}_{2}$ due to the creation of $\mathrm{Ti}^{3+}$ or/and oxygen vacancy at the catalyst surface.

The $\mathrm{Ti}^{3+}$ state on $\mathrm{TiO}_{2}$ surface is important because it can play a similar role as observed in $\mathrm{TiO}_{2}$ doped with metal atoms, which can trap the photogenerated electrons, leaving behind unpaired charges to promote photo-activity [12].

\section{Results and Discussion}

\subsection{Current Intensity During Electrodeposition and Photoelectron Spectroscopy Analysis}

The current regime was studied during the electrodeposition of the oxide to ensure that the nature of the semiconducting layer deposit is a fast diminution of this curve because of its high resistivity and the mode of charge transport. This also helps to calculate the quantity of electricity involved during the process and allows us to evaluate the thickness of the deposited oxide materials layers.

Figures 3 (a-f) illustrate the evolution of the current

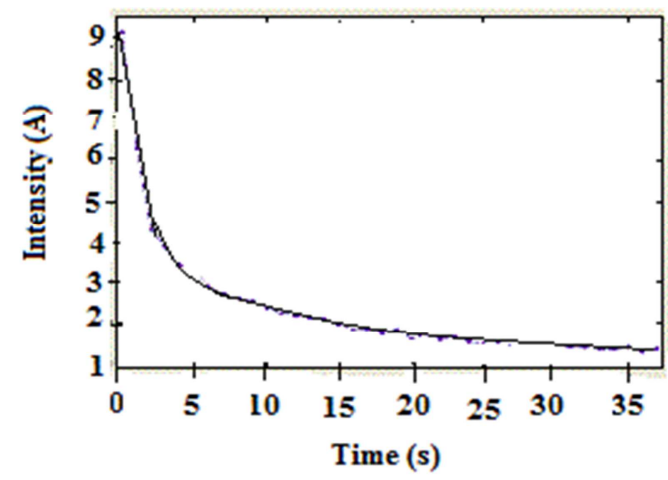

(a) $\mathrm{pH} 0.0$ medium $\mathrm{H}_{2} \mathrm{SO}_{4}, 0,5 \mathrm{~mol} / \mathrm{L}$, anodization tension : $128 \mathrm{~V}$

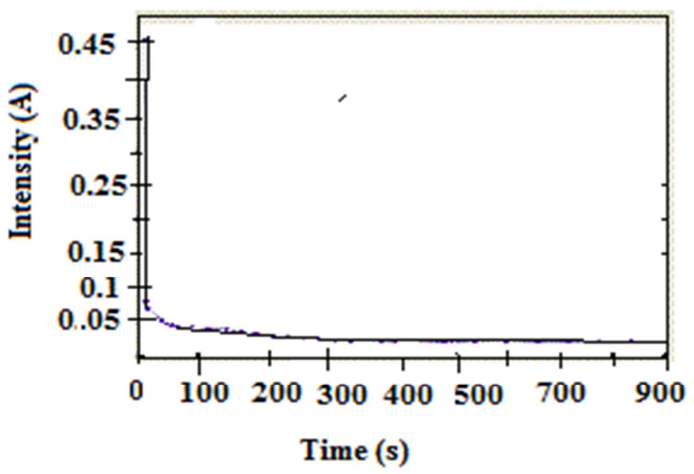

(c) $\mathrm{pH} 3.8$ medium $\mathrm{H}_{2} \mathrm{SO}_{4}, 10^{-4} \mathrm{~mol} / \mathrm{L}$, anodization tension : $128 \mathrm{~V}$ intensity as a function of time during the electrodeposition process. One could observe not only that the current intensity recorded from $\mathrm{TiO}_{2}$ electrode depends on the deposition time and on the nature of the used electrolyte, but also an appearance in two stages. The first one characterized by the current intensity diminution due to the mass transport limitation during the first seconds of electrodeposition process and a second one, the stage of steady-states, where the intensity varies slightly as function of time. During this stage the electrodeposited materials grow into three dimensions. The profile of the current intensity observed in this present study is similar to the one reported in the literature [15]. These current intensities decrease as we approach the neutral $\mathrm{pH}$ : 9.6A $(\mathrm{pH} 0.0) ; 3.5 \mathrm{~A}(\mathrm{pH} \mathrm{1.8)}$; $0.45 \mathrm{~A}(\mathrm{pH} 3.8) ; 0.130 \mathrm{~A}(\mathrm{pH} 0.8) ; 4.9 \mathrm{~A}(\mathrm{pH} 12.8) ; 9.76 \mathrm{~A}(\mathrm{pH}$ $4.0)$. From the Figure 3 one could observe that the average values of current intensities follow the same appearance: 1.8A (pH 0.0); 0.3A (pH 1.8); 25mA (pH 3.8); 4.75mA (pH 5.8); 5mA (pH 7.8); 82.5mA (pH 10.8); 1.7A (pH 12.8); 3.5A ( $\mathrm{pH}$ 4.0). This tendency can be explained by the decrease of free ions as we approach the neutral $\mathrm{pH}$. It is worth to notice the peculiarity shown by the sample anodized in $\mathrm{pH}=10.8$. Indeed, it shows a double profile diminution-landing, this can be explained to a phase transition.

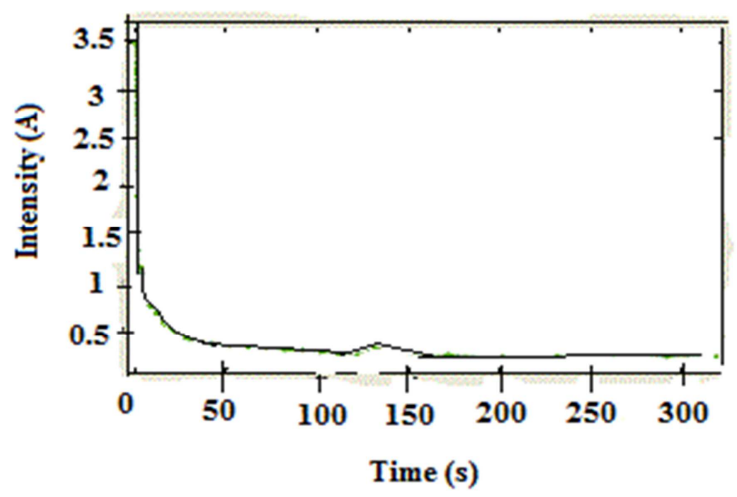

(b) $\mathrm{pH} 1.8$ medium $\mathrm{H}_{2} \mathrm{SO}_{4}, 10^{-2} \mathrm{~mol} / \mathrm{L}$, anodization tension : $128 \mathrm{~V}$

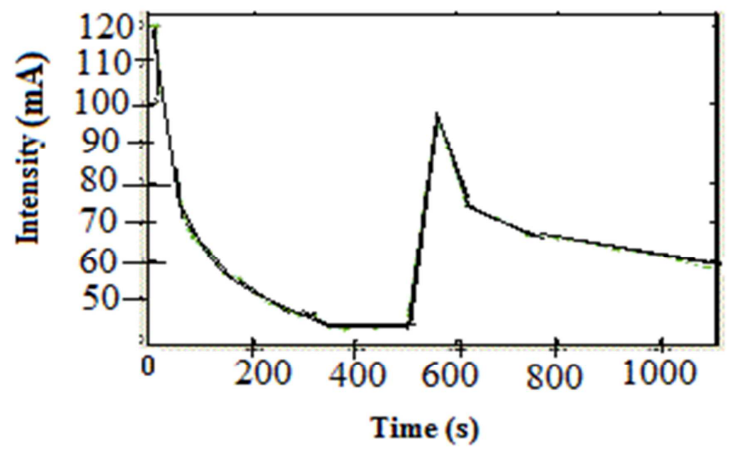

(d) $\mathrm{pH} 10.8$ medium $\mathrm{NaOH}, 6 \times 10^{-4} \mathrm{~mol} / \mathrm{L}$ anodization tension $: 128 \mathrm{~V}$ 

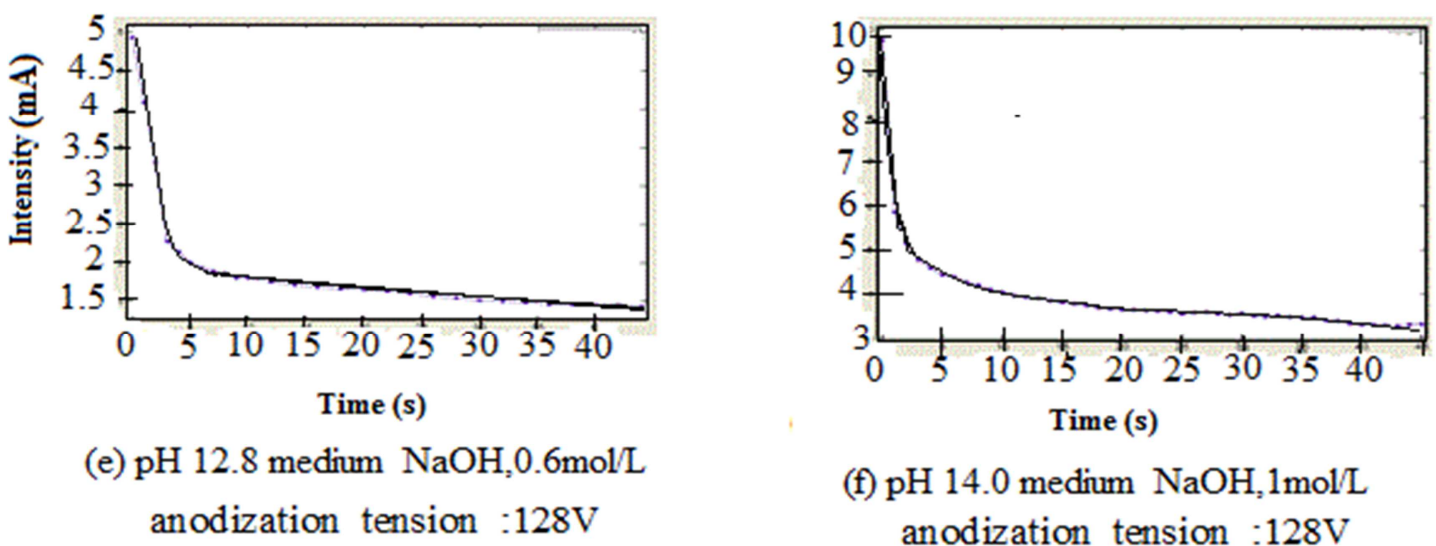

\section{(f) $\mathrm{pH} 14.0$ medium $\mathrm{NaOH}, 1 \mathrm{~mol} / \mathrm{L}$ anodization tension $: 128 \mathrm{~V}$}

Figure 3. Current intensity as a function of time of deposited materials (a-c) in acid and (d-f) in basic solution.

\subsection{Layers Thickness}

To evaluate the thin films thickness the Faraday's law of electrolysis was used by taking into account on the anodization reaction below:

$$
\mathrm{Ti}^{2+}+2 \mathrm{e}^{-} \leftrightarrow \mathrm{Ti}\left(\mathrm{E}^{0}=-1.630 \mathrm{~V}\right) \text { and } \mathrm{TiO}_{2}+4 \mathrm{H}^{+}+2 \mathrm{e}^{-} \leftrightarrow \mathrm{Ti}^{2+}+2 \mathrm{H}_{2} \mathrm{O}\left(\mathrm{E}^{0}=-0.502 \mathrm{~V}\right)
$$

The amount of the deposited mass can be calculated by the formula:

$$
m=\frac{M \times Q}{n \times F} \times \eta
$$

Where, $\mathrm{M}$ is the molecular weight, $\mathrm{n}$ is the number of charge passed during the deposition process, $F$ is the Faraday constant, $\mathrm{Q}$ is the transition charge corresponding to the desired layer thickness, and $\eta$ is the current efficiency. Additionally, the amount of deposited films $m$ can be expressed in terms of current density as:

$$
m=\rho \times A \times d
$$

Where, $A$ is the cathode surface area, $\mathrm{d}$ is the thickness of the deposited layer. By replacing equation (2) into equation (1) the layer thickness of deposited materials can be evaluated [16].

From the experimental results, the deposited mass by coulomb was evaluated to be approximately $2.07 \times 10^{-4} \mathrm{~g} / \mathrm{C}$. The sample's surface was $14.0 \mathrm{~cm}^{2}$. The current efficiency $\eta$ was closed to 0.70 ; the actual value of $\mathrm{d}$ is $0.02542 \times 10^{-4}$ $\mathrm{cm} / \mathrm{C}$. The total charge quantity $(\mathrm{Q})$ has been deducted directly from the current profile, and rated numerically the integral for the duration of electrolysis. Table 1 summarizes the results for all samples.
Table 1. Layer thickness and electric charge for different samples.

\begin{tabular}{ccc}
\hline Sample label & Thickness (nm) & Q (coulombs) \\
\hline 0 & $2078.09 \pm 10$ & 81.70 \\
1 & $2540.30 \pm 12$ & 99.945 \\
2 & $1946.84 \pm 97$ & 76.596 \\
3 & $2595.76 \pm 12$ & 102.127 \\
4 & $2173.15 \pm 10$ & 85.500 \\
5 & $2012.56 \pm 10$ & 79.182 \\
6 & $1982.19 \pm 99$ & 77.987 \\
7 & $4410.40 \pm 22$ & 173.522 \\
\hline
\end{tabular}

\subsection{Measure of Photo-Potential and Charge Rate Versus Time}

Photo-response measurement was carried out by measuring the potential difference induced by the irradiation of the layers, which shows the efficiency with which semiconductor / electrolyte interface charge. The charge rate measures the speed with which the interface capacity charges. Tables 2 and 3 summarize the values obtained for the different samples for anodized layers in acidic solution and those anodized in alkaline solution. Voltages irradiation is taken 20 minutes after the lighting start. All samples have reached the maximum two minutes after the lighting start, except the sample (7), which reached the maximum in only

\begin{tabular}{|c|c|c|c|c|c|c|}
\hline pH & 0.0 & 1.8 & 3.8 & 10.8 & 12.8 & 14.8 \\
\hline Sample label & 0 & 1 & 2 & 5 & 6 & 7 \\
\hline Dark Tension (mV) & 19.0 & 12.8 & 220.0 & 34.0 & 24.0 & 333.0 \\
\hline Irradiation Tension (mV) & 307.0 & 184.0 & 280.0 & 302.0 & 313.0 & 414.0 \\
\hline Difference of potential (mV) & 288.0 & 171.2 & 60.0 & 268.0 & 289.0 & 81.0 \\
\hline
\end{tabular}
one minute.

Table 2. Interface potential value of semiconductor/electrolyte/platinum before and after irradiation. 
Table 3. Interface maximum charge rate value of semiconductor/electrolyte/platinum.

\begin{tabular}{lcccccc}
\hline $\mathbf{p H}$ & $\mathbf{0 . 0}$ & $\mathbf{1 . 8}$ & $\mathbf{3 . 8}$ & $\mathbf{1 0 . 8}$ & $\mathbf{1 2 . 8}$ & $\mathbf{1 4 . 8}$ \\
\hline Sample label & 0 & 1 & 2 & 5 & 6 & 7 \\
Maximum charge rate $(\mathrm{mV} / \mathrm{s})$ & 90.0 & 59.0 & 28.0 & 125.0 & 99.0 & 49.0 \\
\hline
\end{tabular}

In acid solution sample label $(0)$ is the one with the best response and in alkaline solution the samples (5) and (6) are those matching the best answer.

\subsection{Measure of Photo-Current Density}

The current-potential curves were recorded in order to control the current density generated under UV-lamp irradiation. This results show a difference of current potential curves in the dark and under irradiation. This difference reflects the density of free charge carriers photogenerated that reach the surface of the semiconductor [17]. In the case of titanium dioxide, it is precisely this photocurrent density which is directly related to the photo-catalytic activity of this material. The area between the two curves allows evaluating the power generated by the irradiation. The relative influence of the irradiation is therefore evaluated in relation to the difference between the two curves and not in relation to absolute values of the read intensities [18].

In the present investigation the fixed electrode method was used. The anodized layer in alkaline solution showed a very poor adhesion to the substrate; which did allow the measurement of the photocurrent density. Figure 4 displays the current - potential curves for samples anodized in acid solution. These curves not only resumes the results of photocurrent intensities observed for the films in the dark and under the UV irradiation, but also shows similar behavior to that of a conventional semiconductor junction [19]. The maximal value of the tension of polarization is fixed to that of the redox potential of the electrode of $\mathrm{TiO}_{2}$ using platinum as counter electrodes.

A very low reverse current was recorded in the dark and under irradiation. When the prepared samples were polarized in the forward direction, one can observe that the current increases until it reaches the constant value of about 1500 $\mathrm{mV}$. This voltage value is directly related to the Fermi energy. The best response of current intensity was displayed by the sample (0), as shown in Figure 4.

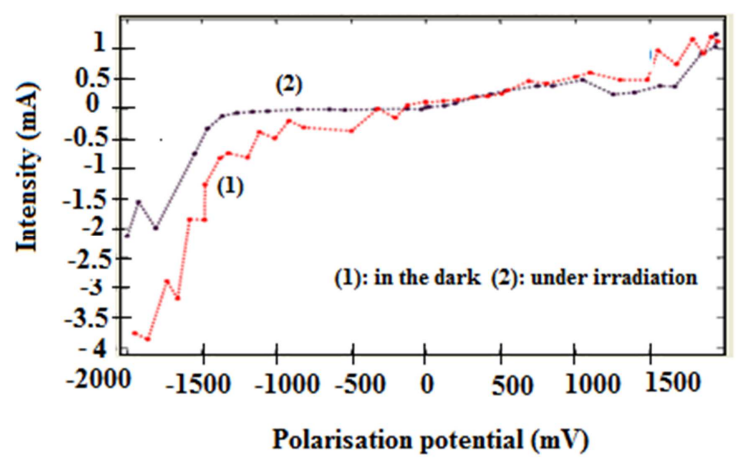

Figure 4. Current- potential curves measured in the dark and under irradiation of sample 0 ( $p H$ 0.0).

\section{Conclusion}

The present investigation was focused on the understanding the photocatalytic properties of titanium dioxide films. The semiconducting layers were prepared by electrodeposition method. The effect of $\mathrm{pH}$ on the photoresponse of the prepared oxide was performed and the films fabricated in the acidic medium displayed a very good stability and adhesion to the metal substrate contrary to those synthetized in alkaline medium, where the coats were easily detached from the film.

The layers prepared in alkaline solution showed the higher charge rate in the $\mathrm{pH}$ range between 10.8 and 12.8. The best charging rate for the films prepared in acid solution was observed for the prepared layer at $\mathrm{pH}=0.0$.

Taking into account all of these parameters, it can be concluded that the acid solution is preferable solution to synthesize titanium dioxide thin layers, especially around the surrounding $\mathrm{pH}=0.0$ where there has been the best shot current - density.

\section{Acknowledgments}

The authors wish to thank the Belgium cooperation for their financial support through the Project No: KIN04.

\section{References}

[1] Ekoko B. G., Jianian Sh, XianRong S, Dong L, Moucheng L, Juan S, Shudian Y, Thin Solid Films, Vol. 515, N 13, (2007) 5287-5297.

[2] K. Wessels, A. Feldhoff, M. Zark et al., Electrochem. SolidState Lett., Vol. 9, (2006) 93-96.

[3] C. A. Morris, M. L. Anderson, R. M. Stroud et al., Science, 284, (1999) 622-624.

[4] L. Davydov, E. P. Amaat and S. P. Georges; US Patent no 6585863,1 July 2.

[5] K. Kiyoshi, Y. Murata, I. Tawara and K. Takeuchi, Proc. Beijing. Int. Symp. Cem. Concr., Internatioal Academic Publishers, 4th Ed, Beinjing, China, (1998) 751-755.

[6] E Sahle-Demessie et al, Nanotechnology, Vol. 27 (28), (2016) 4484.

[7] C. G. B. Garrett and W. H. Brattain, Phys. Rec. 99, (1955) 376-387.

[8] Fujishima and K Honda, Nature, 238, (1972) 37-38; b) Zheng Xie et al., Sci. Technol. Adv. Mater., Vol. 15 (2014) 1-10.

[9] Shiqian Y, Qin W, Manhong Zh et al., Nanotechnology, 21, (2010) 245201-245204. 
[10] N. Chandrasekharam and PV Kamat, Journal of Physical Chemistry B, 104, (2000) 10851.

[11] A. Ahmadl, J. Thiel and S. Ismat, IOP Publishing Journal of Physics: Conference Series 61, (2007) 11-15.

[12] Ekoko G B., JK-K. Lobo, O M. Mvele, A K. Mbongo, J L. Muswema and C Z. Lefuni,, South African Journal of Chemistry, 66, (2013) 1-6.

[13] Ekoko B G., J K. K. Lobo, OM. Mvele, J L. Muswema, J S. Yamambe, American Journal of Physical Chemistry, 3 (4), (2014) 41-46.

[14] Ekoko B, Lobo K K, Mvele M, Mbongo K, Muswema La, Mangwala K,, Pan African and South African Meeting of the International Year of Crystallography (IYCr2014 Africa), 1217 Octobre (2014), Bloemfontein, South Africa.
[15] Niede K. Kuromoto, A. Renata Simão, A. Gloria Soares; Materials Characterization, ed. Elsevier, (2007) 58.

[16] a) A. Kazadi Mukenga B et al., J. Appl. Phys., 89 (6), (2001) 3393; b) A. Kazadi Mukenga B et al., A. Phys. Rev., Vol. 9, (2015) 487.

[17] Adir Bar Lev, Semiconductor and electronic devices, Prentice Hall International, (1979) 109-110.

[18] J R Martin, R Olier et P Clechet, Journal de Physique, Colloque C5, supplément au no 11; Tome 38, novembre (1977) 25-27.

[19] J P Colinge et fernand Van de Wiele, Physique des dispositifs semi-conducteurs, De Boeck Université, (1996) 33-3. 